\title{
A Comparative Study between English and Bangla Vowel System
}

\author{
A. K. M. Mazharul Islam \\ Lecturer- English Language Centre- Department of English- College of Languages and Translation- \\ King Khalid University-KSA \\ amazharul@kku. edu. sa
}

\begin{abstract}
This paper briefly investigates the vowel sounds of English and Bangla language. Keeping the supra-segmental features aside, it mainly focuses on the major segmental similarities and differences of the vowel sound system of these two languages. The paper explores the articulatory system in brief and reviews the vowels sounds of English. An effort has been made to pinpoint and enumerate the difficulties faced by the Bangladeshi learners of English. To do that a group of learners is interviewed giving them words in context and without. Interestingly, a considerable portion of the difficulties of the learners might be attributed to the differences of the vowel system of these two languages. Though not complete and detailed, the writing finally leaves some pedagogical suggestions hoping to contribute to the present teaching and learning of English in general and in Bangladesh in particular.
\end{abstract}

Keywords: Vowel sounds, English and Bangla vowels, learners' difficulties, teaching English in Bangladesh

\section{Introduction}

Language is the 'species-specific' and 'species-uniform' feature of the human being (Varshney, 2000) and vowels are the nucleus of any language. A proper understanding of the vowels is at the root of expertise in phonetics. Vowels are the center of the words upon which the whole building of language is built. Hence, Learning and understanding the vowels is of pivotal.

This paper tries to present a clear concept of the vowels, its categories and their various features in detail. It focuses on to diagnose the problems of Bangladeshi learners of English vis-à-vis the vowel sounds. The paper looks for some probable solutions to the problems.

\section{The Concept of Vowel}

The traditional concept of vowel a Bangladeshi learner of English grows up with is learning "a, $\mathrm{e}, \mathrm{i}, \mathrm{o}, \mathrm{u}$ " as vowels. Our concern, of course, surpasses this narrow limit and tends towards the vowel sounds which are not less than twenty-four in numbers and are bewilderingly various and tricky in nature.

A vowel is a 'hum' or a tune which is produced with the thrown air stream of the lungs and finds no obstacle anywhere from the voice-box to lips and no audible friction is caused. In other words, "vowels are sounds in which there is no obstruction to the flow of air as it passes from the larynx to the lips (Roach,2000). It can also be like - A vowel is a sound which is produced when air escapes centrally through oral cavity without any obstruction. Let us look at still another dictionary definition of a vowel - (in English articulation) a speech sound produced without occluding, diverting, or obstructing the flow of air from the lungs. So we can say that vowels are sounds which are articulated without any obstruction, partial or complete, in the oral cavity. 


\section{Vowel Production Mechanism}

The production of any sound is not as simple as mere opening and closing the mouth. It is a rather complex process. There three stages are involved here- psychological, physiological and physical (Sethi and Dhamija, 1998). Let us be acquainted with them very briefly. In the psychological stage, when we try to produce any sound then a group brain cells are excited and a message is formed. Then in the physiological level, the message is carried to the diaphragm. In the third level, which is at the physical level, the message is passed to the diaphragm. The diaphragm gives a squeeze and a flow of air rushes out through the windpipe and finally released either through the oral cavity or nasal cavity. In the case of consonant sounds, the flow of the air is obstructed almost at a dozen places and different consonant sounds are produced. But regarding vowel sounds that flow of air is not hindered anywhere and directly let out in the air (Yule, 2008). Following figures would help us to understand the difference between the production of consonant and vowel sounds. The flow of the air is being played by a group of active and passive articulators for producing consonant sounds. Figure 1(a) displays the points where the air stream is obstructed for consonant sounds. Figure 1(b) shows that the air stream is directly emitted to the air without having in blockage or obstruction for the production of vowel sounds.

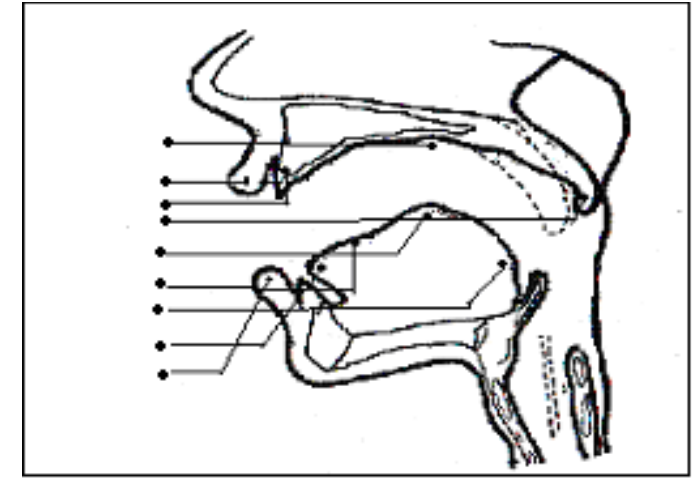

Figure1(a): points of obstruction

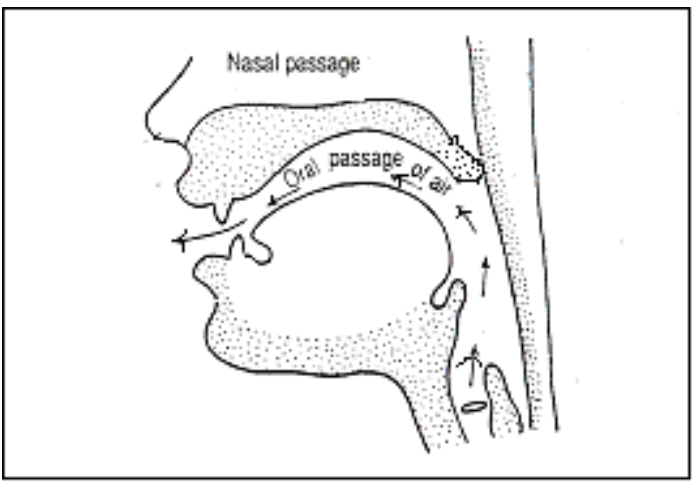

Figure1(b): free air-stream

\section{Features of Vowels:}

Vowels are essentially a hum which is issued from the glottis with the vocal folds normally vibrating. In the production of vowel sounds, there would be no obstruction to the air flow and no hissing sound or friction would be there (Carr, 2003). We are to carry in mind that various remarkable features are added to the vowels by three factors - tongue advancement, tongue height and lip position. Let us try to enumerate some characteristics of vowels in the following manner:

- All vowels are oral

- A vowel can stand alone without the help of any consonant sound.

- The vowels are vocoids.

- All the vowels are voiced.

- There is no pure nasal vowel in English but they can be nasalized.

- They are the soul of a syllable.

- The quality of a vowel sound changes with change of tongue height, tongue advancement and lip rounding

- They differ from one another in respect of quality or quantity or the both

- Gliding vowels or diphthongs consists of two monophthongs produced after one another. 


\section{Tree of the Vowels:}

Before going to minute details of the vowels let us have a look of all the vowels in a tree diagram. It will make the review the vowels easier.

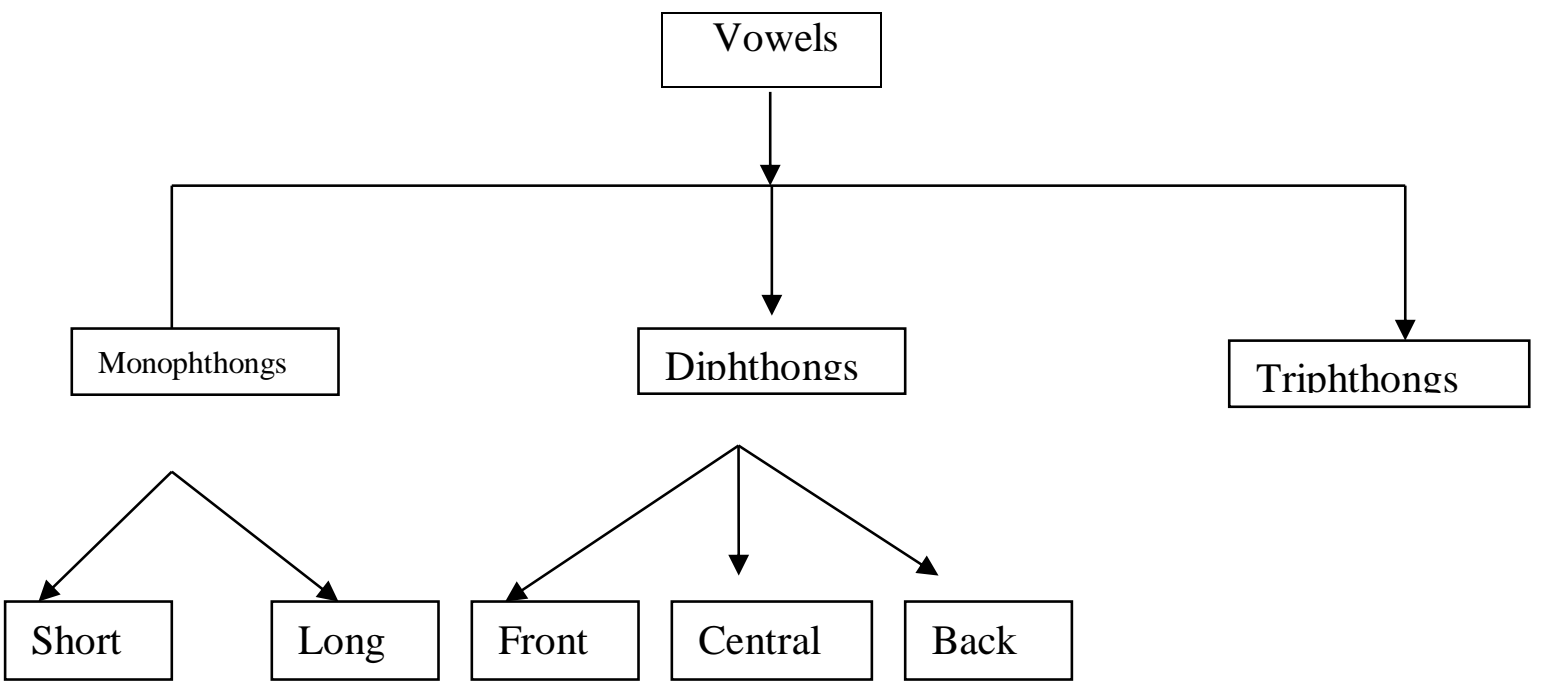

Figure(2): Tree of Vowels

\section{Description of the Vowels:}

Before plunging deeper into the English vowels let us have a brief idea about the extreme territory of all the vowels that human vocal system can produce. They are usually called cardinal vowels (Roach,2000). They help a learner to describe, classify and compare vowels of all languages. No vowels can be produced farther beyond this borderline. They are eight in number. Cardinal vowel no. is [i] utmost front close vowel and [u] is the utmost back close vowel and the rest of them are set in between. The cardinal vowels are shown within square brackets. The figure that follows would help our understanding.

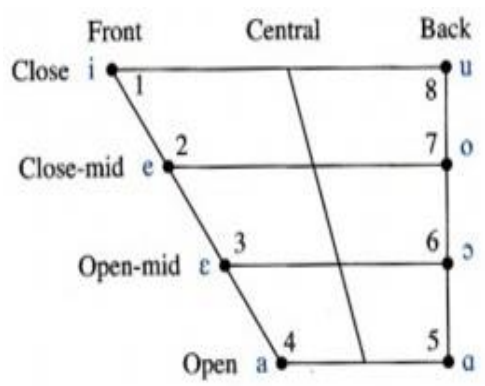

Figure(3): Primary Cardinal Vowels

Vowels in English can first be divided into two categories - pure vowels or monophthongs and gliding vowels or diphthongs. Yet there is a third kind of vowels which can be called triphthongs or double gliding vowels (Roach, 2000). First division that is made among the vowels is on the basis of quantity or length. They are usually shown within slashes /I/. From this large range of vowels let us aim at the short vowels first. 


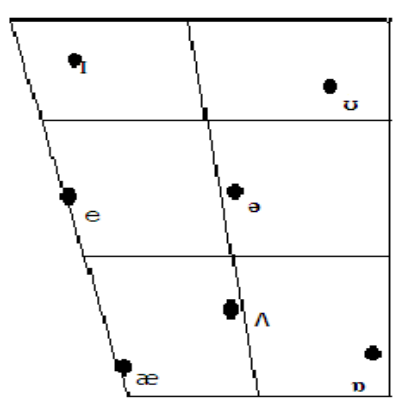

Figure(4): Short vowels

\section{Short Vowels:}

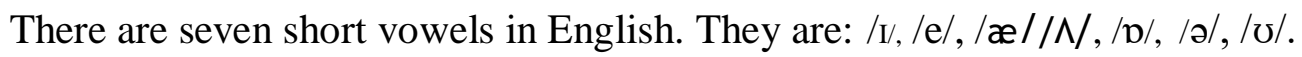

- The sound $\mathbf{I}$ is a close front one and is the mid sound of the words bit, pit, and fish. In comparison to cardinal vowel [i], this one is more open and closer to center.

- Mid vowel sound of the words 'bet' 'men' and 'red' is /e/. This front vowel can be traced between cardinal 2 [e] and cardinal vowel $3[\varepsilon]$. The lips remain a slightly spread.

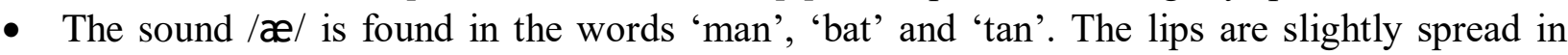
producing this sound and it is not as open as cardinal vowel no. [a].

- The sound $/ \mathbf{\Lambda} /$ is found in the words 'but', 'some' and 'rush'. This one is a central vowel and relatively open.

- The middle sound in the words 'pot', 'gone' and 'cross' is / $\mathrm{p} /$. This vowel is almost at the back. The lips are slightly rounded.

- The sound $/ \boldsymbol{\sigma} /$ is found in the words 'pull' 'push' and 'put'. The cardinal vowel $8[\mathrm{u}]$ is the nearest to it but it is more open and nearer to center. The lips are rounded.

- The initial vowel sound of the words 'about' 'above' and 'oppose' is / //. It is called schwa. This vowel sound is most frequently used and shortest among all other vowels.

\section{Long Vowels:}

There are five long vowels. They differ from the short vowels in quantity. In a similar context, they are made long. To mean the long vowel two dots are added to the symbol. They are: /i:/, /3:/, /a:/, /s:/ and /u:/.

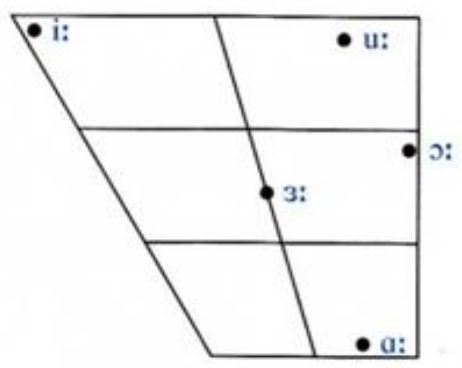

Figure(5): Long Vowels

\begin{tabular}{|c|c|c|c|c|c|}
\hline & $\begin{array}{l}\text { Tongue } \\
\text { height }\end{array}$ & $\begin{array}{l}\text { Tongue } \\
\text { advancement }\end{array}$ & Lips & words & Transcription \\
\hline /i:/ & close & front & spread & Beat, sea, mean & /bi:t/ \\
\hline /a:/ & open & back & neutral & Card, father, pass & /ka:d/ \\
\hline / ०:/ & Mid-close & back & rounding & Torn, board, saw & $/ \mathrm{t}$ o:n/ \\
\hline /u:/ & close & back & rounding & Food, soon, loose & /fu:d/ \\
\hline
\end{tabular}


If we go to compare the long vowels with the cardinal vowels we would see that long vowel /i:/ is closer to cardinal vowel [i] than short vowel/I/. Long vowel /3:/ is nearer to cardinal vowel $3[\varepsilon]$ but it is more central. Long vowel /a:/ is almost similar to cardinal vowel 5 [a] but is less back. Long vowel /o:/ is found somewhere in between cardinal vowel $6[0]$ and 7 [o]. The nearest cardinal vowel this long vowel /u:/ is cardinal vowel $8[\mathrm{u}]$ but it less back and less close.

\section{Diphthongs:}

In diphthongs, we find the presence of two pure vowels but they are not separated from each other. There is a glide from one towards the other(Davenport and Hannahs,2010). The word 'diphthong' comes from Greek and means 'two sounds'. In fact, although diphthong phonemes in both English and Bengali are composed of two sounds, they are usually spoken so closely together that they can for all practical purposes be regarded as one sound (Hai and Ball, 1962).

Regarding length or quantity, they are like long vowels. The first part of the diphthongs is much stronger and longer. There are eight diphthongs in English. Depending on their ending vowels they can be divided into three categories. They are: front, central and back. They can be shown in following tree diagram.

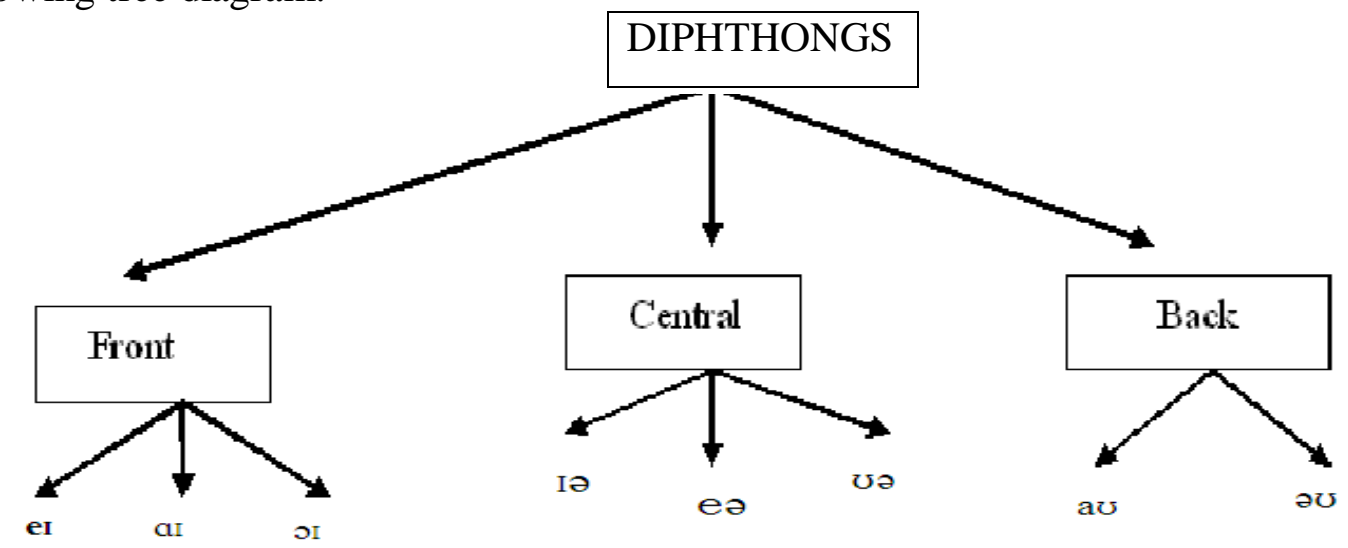

Figure(6): Tree diagram of diphthongs

Adding /a/ sound to the five closing vowels still a third kind of vowel is there which are called triphthongs ( Roach, 2000) and are the most complex of the vowel types. They are usually a combination of three vowel sounds. In a triphthong, the glide is from one vowel to the second and yet to the third. They are as follow:

$$
\begin{aligned}
& \text { eI+ } \partial=\text { eIə(player) } \\
& a \mathbf{I}+\partial=a \mathbf{I} \partial \text { (fire) } \\
& \mathrm{\jmath}+\boldsymbol{I}=\boldsymbol{\jmath} \mathbf{I} \text { (loyal) } \\
& \text { əひ+ə }=\text { ə๗ə (lower) } \\
& \mathrm{a} \mho+ə=\mathrm{a} ə \text { (power) }
\end{aligned}
$$

\section{The difference between English and Bengali Vowels:}

To be aware of the difficulties of Bangladeshi learners of English we are to be familiar with the differences between Bengali and English vowels. There are some vowels of English which are not present in Bengali and the Vice Versa (Hai and Ball, 1962). In Bengali alphabet, long and short is mentioned but it is not maintained in pronunciation. The intermingling between short and long vowel does not make any difference in meaning but in English, it is not likely. The use of short vowels in place of long ones and the vice versa may be a blunder. The meaning may be altogether different with the change of long and short vowel. Diphthongs of these two languages are also not the same. There are eighteen regular diphthongs in Bengali which is far a greater number than English 
diphthongs. Another point of difference is unlike English vowels Bangla vowels can be nasalized and can affect the meaning (Haiand Ball, 1962). The following table can be helpful:

Table(1): Difference between Bangla and English Vowel Sounds

\begin{tabular}{|c|c|c|c|}
\hline Phonetic Symbol & English & Bangla & Key Word \\
\hline $\mathrm{i}:$ & $\sqrt{ }$ & $x$ & feel \\
\hline $\mathrm{i}$ & $x$ & $\sqrt{ }$ & chi 1 (wPj) \\
\hline i & $\sqrt{ }$ & $x$ & fill \\
\hline $\mathrm{e}$ & $\sqrt{ }$ & $\sqrt{ }$ & bed \\
\hline$æ$ & $\sqrt{ }$ & $\sqrt{ }$ & cat \\
\hline $\mathrm{a}$ & $x$ & $\sqrt{ }$ & bhat (fvZ) \\
\hline a: & $\sqrt{ }$ & $x$ & part \\
\hline 0 & $\sqrt{ }$ & $\sqrt{ }$ & hot \\
\hline $\mathrm{o}$ & $x$ & $\sqrt{ }$ & gol(†Mvj) \\
\hline $\mathrm{u}$ & $\sqrt{ }$ & $x$ & full \\
\hline $\mathrm{u}:$ & $\sqrt{ }$ & $x$ & fool \\
\hline $\mathrm{u}$ & $x$ & $\sqrt{ }$ & chul (Pzj) \\
\hline$\Lambda$ & $\sqrt{ }$ & $x$ & but \\
\hline 3:/2: & $\sqrt{ }$ & $x$ & third \\
\hline$\partial$ & $\sqrt{ }$ & $x$ & above \\
\hline ๑: & $\sqrt{ }$ & $x$ & saw \\
\hline
\end{tabular}

The following quadrant would help us to understand the comparative spots where from the vowels of two languages are produced. Some of the vowels conform in their positions but some are not identical.

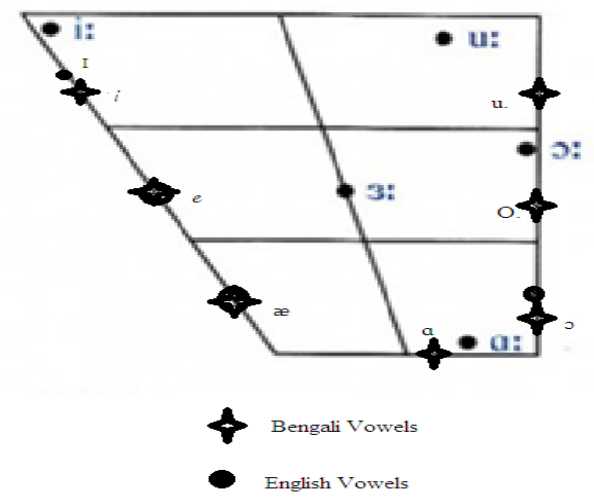

Figure(7): The relative position of Bangla and English vowels

\section{Data Collection and Analysis:}

A sum of 45 students was randomly chosen from three private and public universities. They were first-year first semester students of English Department and they had not received any lessons of phonetics in the university yet or any other level of their education. One thing may be worth mentionable here, phonetics and English phonology are not included to teach in the syllabus in the primary or secondary level in Bangladeshi. The students were asked to read aloud a passage where the basic words with the vowels were used. Their voice was recorded and analyzed. The students were informed afterward about the recording and they consented to use their voice for research purpose.

\section{Problems of Bangladeshi Learners of English with English Vowels:}

A speaker's articulators usually get set with the sounds of his/her mother tongue. When he tries to learn a language other than his mother tongue then he faces problems with those sounds specially that are not found in his mother tongue. O'Connor (1998) mentions a list of problems of consonants 
and vowels of Hindi speakers. In respect of the vowels, the problematic sounds he notes are /e/, /3:/,

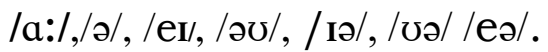

In a greater perspective, Bangladeshi learners also share the same difficulties to a considerable extent. A number of problems of Bangladeshi learners may be traced regarding vowel sounds. One of the remarkable problems of learners of English is L1 interference that is; his mother tongue vowels often intrude into the target language vowels. Another problem is that the learners cannot handle long and short vowels. In Bangla long and short vowel do not make any difference in meaning. In English, they are very crucial. Some of the vowels in English are not there in Bengali. Schwa ' $\partial$ 'is a characteristic sound which becomes very tough for the learners. Long vowels /3:/,/o:/ are also difficult to tackle. Another noticeable difficult area for the learners is diphthongs. The common mistake that is made by the learners is that they only say the first part of the diphthong and ignore the second part and in consequence, they sound like a short vowel. The English vowel sounds

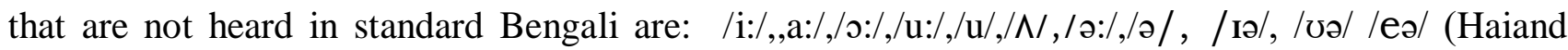
Ball, 1962). In the following chart we can show the major difficulties in brief:

Table(2): Major Difficulties of the Bangladeshi learners

\begin{tabular}{|c|c|c|c|}
\hline Sounds in English & Example in words & $\begin{array}{l}\text { Correct } \\
\text { pronunciation }\end{array}$ & Attempt of the learners and notes \\
\hline $\mathrm{i}:, \mathrm{i}$ & Feel, fill & /fi:l/,/fIl & $\begin{array}{l}\text { /fi l/ both long and short becomes the same, } \\
\text { they use their only vowel }\end{array}$ \\
\hline $\mathrm{a}:, \Lambda, 3:$ & bard, bud, bird & $\begin{array}{l}\text { /ba:d/, } \quad \text { /b/d/, } \\
/ \mathrm{b}_{3}: \mathrm{d} /\end{array}$ & /bad/; in all cases they use only /a/ sound \\
\hline$\partial$ & about & $/ \mathrm{\partial b} \wedge \mathrm{v} /$ & $/ æ b \boldsymbol{L} \mathbf{v} /$; learners use $3^{\text {rd }}$ Bengali vowel \\
\hline o: & saw & /so:/ & /so / learners use their own vowel 5 \\
\hline $\mathrm{u}, \mathrm{u}:$ & full, fool & /ful/, /fu:l/ & $\begin{array}{l}\text { /ful/ ; both cases only Bangla vowel no } 7 \text { is } \\
\text { used }\end{array}$ \\
\hline еə, Іə, иə & air, fear, poor & /eə/, /fIə/, /puə/ & $\begin{array}{l}\text { The learners usually break the diphthongs in } \\
\text { their own vowels and first made long; } \\
\text { becomes very different from the right one }\end{array}$ \\
\hline
\end{tabular}

\section{Analysis}

The difficulties of the Bangladeshi learners can be summarized. Firstly, they fail to differentiate between short and long vowel. They replace the both with a single mother tongue vowel. Another problem for them is the mid vowel ' $ə$ '. It is usually replaced by third Bengali vowel 'æ'. Still another point of the obstacle is with the diphthongs where the learners usually break the vowels into two different vowels. They pronounce them separately as different vowels. Either sometimes, they pronounce the initial vowel very clearly and leave the other completely. Accordingly, all these create a lot of confusion and misunderstanding. It becomes very clear while a native speaker is communicated.

\section{Recommendation}

Surely, it is not very easy to master all the sounds of a language which is not one's mother tongue. The first job is to become aware of shortcomings. Once the problems are diagnosed then they can be faced easily. To handle them, we can try the following suggestions:

- Making the learners aware of the differences of the vowel sound of two languages

- Making the learners aware of their difficulties

- Making the learners aware of all the vowel sounds along with their place and manner of articulation

- Finding out major problematic sounds

- Treat them one by one

- Providing them with regular reinforcement

- Providing them a native or native-like model 
- Training the instructors

- Providing an exposure

- Introducing phonetics to the learners in the primary level of education

\section{Conclusion}

The vowels are really tricky. When English is not one's mother tongue, to learn the vowels of the language is not an easy job surely. Receiving proper guidance a careful and enthusiastic reader may easily acquire them with expected accuracy. Taking into consideration the offered suggestions, one can minimize the obstacles and can maximize his learning of the vowels to the desired extent if not exactly like the natives. Our effort has been to focus the English vowels in a bit longer detail and to find out problems of the Bangladeshi learners with them and to think for some solutions. This writing is not a propagation of any theory anyway. It might have some limitations too. Yet, it is expected that the learners of phonetics in general, especially of Bangladesh, can benefit from this writing.

\section{References:}

[1] Carr, Philip. English Phonetics and Phonology: An Introduction,(2003).

[2] Celce-Murcia, Marianne, Britton, Donna M \& Godwin, Janet M. (1996), Teaching Pronunciation: A Reference for Teachers of English to Speakers of Other Languages, UK: Cambridge University Press, 32(4)(1998),783-784, https://doi.org/10.2307/3588013

[3] Davenport, Mike \& S. J. Hannahs, Introducing Phonetics and Phonology $\left(3^{\text {rd }}\right)$. UK: Routledge, (2010)

[4] Fromkin, Victoria \& Robert Rodman, An Introduction to Language.(6 ${ }^{\text {th }}$ ed). USA: Harcourt Brace College Publishers, (1998)

[5] Hai, Muhammad A. \& W. J. Ball, The Sound Structures of English and Bengali. Dhaka: Dhaka University Press,38(4)(1962),460-462, https://doi.org/10.2307/410687

[6] O'Connor, J. D, Better English Pronunciation. UK: Cambridge University Press,(1998).

[7] Roach, Peter, English Phonetics and Phonology. UK: Cambridge University Press,(2000)

[8] Sethi, J \& P. V. Dhamija, A Course in Phonetics and Spoken English. India: Prentice hall Private Limited, (1998)

[9] Varshney, R.L., An Introductory Text Book of Linguistics and Phonetics. Bareilly: Student Store, (2000)

[10] Yule, George, The Study of Language. (3rded) India: Cambridge University Press, (2008) 